Western University

Scholarship@Western

FIMS Publications

Information \& Media Studies (FIMS) Faculty

2015

Differences Over Discourse Structure Differences: A Reply to Urquhart and Urquhart

Jennie A. Abrahamson

Western University

Victoria L. Rubin

Western University,vrubin@uwo.ca

Follow this and additional works at: https://ir.lib.uwo.ca/fimspub

Part of the Library and Information Science Commons

Citation of this paper:

Abrahamson, Jennie A. and Rubin, Victoria L., "Differences Over Discourse Structure Differences: A Reply to Urquhart and Urquhart" (2015). FIMS Publications. 89.

https://ir.lib.uwo.ca/fimspub/89 


\title{
Differences Over Discourse Structure Differences: A Reply to Urquhart and Urquhart
}

\author{
PREPRINT \\ Jennie A. Abrahamson and Victoria L. Rubin \\ Faculty of Information and Media Studies \\ Language \& information Technology Research Lab (LiT.RL) \\ The University of Western Ontario, London, Canada
}

\begin{abstract}
Purpose - In this paper we respond to Urquhart and Urquhart's critique of our previous work entitled "Discourse structure differences in lay and professional health communication", published in this journal in 2012 (Vol. 68 No. 6, pp.826 - 851, doi: 10.1108/00220411211277064).

Design/methodology/approach - We examine Urquhart and Urquhart's critique and provide responses to their concerns and cautionary remarks against cross-disciplinary contributions. We reiterate our central claim.
\end{abstract}

Findings - We argue that Mann and Thompson's $(1987,1988)$ Rhetorical Structure Theory (RST) offers valuable insights into computer-mediated health communication and deserves further discussion of its methodological strength and weaknesses for application in LIS.

Research limitations/implications - While we agree that some methodological limitations pointed out by Urquhart and Urquhart are valid, we take this opportunity to correct certain misunderstandings and misstatements.

Originality/value - We argue for continued use of innovative techniques borrowed from neighboring disciplines, in spite of objections from the researchers accustomed to a familiar strand of literature. We encourage researchers to consider RST and other computational linguistics-based discourse analysis annotation frameworks that could provide the basis for integrated research, and eventual applications in information behaviour and information retrieval. 


\section{Introduction}

We thank Urquhart and Urquhart for their detailed and enthusiastic consideration of our recent work (Abrahamson and Rubin, 2012), and for opening the debate on the use of the Rhetorical Structure Theory in library and information science (LIS) research. One of our objectives was to foster further discussion and research in LIS on all aspects of the work represented, particularly in integrated approaches to information behaviour and information retrieval system research, and use of a pragmatics-level linguistics approach in health communication and information use. After providing a brief background, we respond to several of Urquhart and Urquhart's concerns.

\section{Background and Our Central Claim}

In Abrahamson and Rubin (2012) we positioned our research in the context of laypeople seeking healthrelated information via public consumer health websites. We collected a sample of comparable lay (consumer) and professional (physician) online responses to health-related questions about living with the chronic disease, diabetes. We systematically compared the discourse structures in the peer consumer and physician answers, applying Mann and Thompson's $(1987,1988)$ Rhetorical Structure Theory (RST) as the analytical framework. We also considered whether one source of information (or discourse) encourages adherence to healthy behaviour more effectively than another (consumer versus physician), from an RST, or linguistics-based perspective. The data sample was examined for prevalence of RST relations and their rhetorical effects. Mann and Thompson $(1987,1988)$ distinguish two broad types of the RST relations: 1 ) presentational relations that are considered pragmatic (i.e. contributing to the achievement of a goal, or information use) and 2) subject matter relations that are viewed as mostly semantic (i.e. putting forth a factual level argument, or fulfilling the purpose of information acquisition).

Based on the most prevalent RST relations found in each discourse and their defined RST effects, we concluded that the consumer answer discourse may be more effective (rhetorically) at facilitating healthy behaviour in fellow consumers than the physician answer discourse. We saw the physician answer discourse as "perhaps more literally informative, in that it provides more information, though not about how to use or integrate that information into everyday life" (Abrahamson and Rubin, 2012, p. 843). To support our central claims, we discuss distribution of most common RST relations in consumer and physician answers, and their proposed RST effects:

"[T]he majority of consumer answer discourse relations were presentational [and that] suggests that the consumer answers may be more able to trigger a response action in readers or users of shared information. For example, the significance of the most prevalent consumer discourse prelation, Motivation [24 per cent versus 3.5 per cent in physician data], is that it represents textual information that may increase the reader's desire or inclination to perform an action (Mann and Taboada, 2010a), such as a healthy behaviour, like walking. ...The second and third most common consumer discourse relations also demonstrate that the consumer discourse is more polite [linguistically] due to the frequency of the Concession relation (11 per cent of consumer; 3.5 per cent of physician relations), and more enabling (in the sense of making actions/decisions more feasible or possible by supplying means, knowledge or opportunity) due to the Enablement relation (9 per cent of consumer; 1.7 per cent of physician relations ( $p .843$ )

... [By contrast, the most common RST relation in physician answers in the examined sample was that of Elaboration (27 per cent versus 6 per cent in consumer answers).] The prevalence of the Condition relation, the second most common physician relation compared to findings in the consumer discourse (11 per cent versus 4 per cent) indicates that the physician discourse is more 
reliant on establishing or sharing facts for developing or couching (literally, conditioning) arguments or shared information. The frequency of the other second most common physician relation, the Background relation (11 per cent in physician; 6 per cent in consumer data), demonstrate physician intention to help (or concern about the need to help) consumers comprehend health information" (p. 844).

Tentatively connecting adherence behaviour with defined RST relation effects, we called for further empirical tests of the idea, and acknowledged that some consumers "may actually prefer the physician answer discourse, precisely for its more descriptive nature" (p. 846). It is also worth mentioning that we called for further comparisons of the two dichotomies: the presentational versus subject matter relations in RST, and possible connections with the constructionist theoretical approach and the information transfer model in LIS.

\section{Critique Rebuttal}

We agree with some methodological limitations pointed out by Urquhart and Urquhart and have explicitly acknowledged most of them in the limitations section of our paper (Abrahamson and Rubin, 2012). Specifically, we noted the limited sample size which restricts the generalizability of the findings, and the need for greater diversity for all participants and multiple voices in physician data sources for future studies. We regret that our wording was confusing on the number of answers/posts and the number of consumer participants studied. There were, in fact, 10 consumer answer threads and 10 physician answer threads. Consumer threads ranged from one to five answer posts per thread, for a total of 26 consumer answer posts. Eleven posts were written by 11 unique authors (each contributing one post) and 3 more productive authors contributed the remaining 15 out of 26 posts. Physician answer threads each had one answer/post per thread.

At the same time, we wish to point out certain misunderstandings, starting with the confusion about our central claim and proceeding in roughly chronological order.

\subsection{Efficiency and Effects}

Urquhart and Urquhart state incorrectly that we found that consumer to consumer texts may be more "efficient" than physician to consumer texts. We do not discuss efficiency in our paper. We do, however, discuss RST "effects," as part of the RST framework, though our research design prohibits us from drawing conclusions related in any way to actual cause or effect for health or information use outcomes. Instead, we carefully observed and reported on our findings regarding differences identified between the two discourses (consumer and physician), guided by the RST theoretical framework definitions and related, but unconfirmed effects. Echoing Mann and Thompson (2006a, p. 432), we affirm the need for direct user (reader) feedback regarding RST's user (reader) "effects" and information sharer "intentions." Moreover, we make no claim that consumers are superior to physicians as information sources for fellow consumers, though agree that perhaps we could have worded this more clearly. Any observations we make are related to effects implied by the RST framework. We respect that physician communication can be affected by their professional responsibilities and conduct requirements, which are quite different from the consumer's everyday life communication, as we observed on p. 844 (Abrahamson and Rubin, 2012). Our overall purpose was to explore consumer-to-consumer health communication in order to understand it better within the domain of adherence and chronic disease, via comparing it to physician-to-consumer health communication on the website studied. 


\subsection{Scope of Reviewed Literature}

Fleischman observes that "a lot has been written on language and medicine" (2001, p. 470). The Heritage and Maynard (2006) article that Urquhart and Urquhart cite would indeed be helpful as a "further reading" or "cf." reference for readers wishing to explore the literature on physician-patient interaction. For this study, we considered, where, in their everyday life patients/consumers might look for or encounter information (beyond the medical clinic or hospital). Facing space limitations and in alignment with our research objectives, we focused our literature review on adherence and on consumer-to-consumer interaction and peer-to-peer information sharing in everyday health information behaviour.

\subsection{Rhetorical Structure Theory as Analytical Framework}

Urquhart and Urquhart provide useful discussion of RST as a methodology, beyond what we had room for in our empirical research report. Questioning the technical name of RST - namely, whether it deserves to be a theory or not - is an interesting move on behalf of our critics, yet perhaps an inconsequential technicality in view of the RST's operationalized use. RST deserves a careful decomposition of its strength and weaknesses; there is certainly room in the LIS literature for an article on RST and its applicability to LIS research. Though RST may appear too new in some circles, there is a substantial and growing body of literature that uses RST for discourse level analysis of textual data (cf., Taboada and Mann, 2006a; Mann and Taboada, 2010b).

Our lab has successfully used RST, for instance, to analyze computer-mediated personal stories to discern truthful stories from deceptive ones (Rubin and Vashchilko 2012, Rubin and Lukioanova, In Press). This and many other works (see Taboada and Mann, 2006b for a summary of earlier works) testify to the general acceptance of the validity of the RST and its procedures in disciplines such as computational linguistics and natural language processing.

Though RST has been used extensively to systematically analyze text by hand, Urquhart and Urquhart rightfully notice the need to operationalize and normalize the procedure for segmenting the RST units of analysis (also called, Elementary Discourse Units or EDUs) such as individual clauses or phrases. This and other limitations (such as the potential for subjective interpretation in assigning one type of relation over another) can be addressed with automated approaches, as well as observance of strict qualitative and RST-specific research protocols such as those implemented in the present study (and cf., Taboada, 2004; Bateman and Delin, 2006). There have been recent efforts to fully automate RST analysis based on marked linguistic features. The HILDA discourse parser was proposed by Hernault, Prendinger, duVerle, and Ishizuka (2010) as the first fully implemented text-level discourse parser. It was later extended by Feng and Hirst (2012) by adding original rich linguistic features as well as those suggested by Lin, Kan and Ng (2009). "With time and continued improvements, the subjectivity in establishing of rhetorical relations by manual coders will become less of a challenge as the task is being systematized algorithmically"(Rubin \& Lukoianova, In Press)."

\subsection{Pragmatics: The Study of Language in Use}

Urquhart and Urquhart's assertion that we claim our study is original because it is "the first to use discourse analysis" is incorrect. We specifically claim that our study is novel due to our use of a computational linguistics-based, pragmatics approach, utilizing RST, to study health information behaviour (Abrahamson and Rubin, 2012, p. 828). We note, though, that there are a few studies on health promotion that have used RST (cf., Mann and Taboada, 2010b). Also, after publishing our original paper, we found a paper by Belkin, et al. (1995) that discussed using RST as a component of information retrieval system development. 


\subsection{Specific RST Relation Assignment}

Urquhart and Urquhart highlight the challenge of distinguishing between the RST relations "Motivation" and "Condition." They identify the text below as a physician answer text from our paper; in fact, it is (and is labelled as such), a consumer answer text. They propose that the text below should be a Condition relation, not a Motivation relation, as we analyzed it to be (Abrahamson and Rubin, 2012, p. 841).

Here is the Motivation relation we analyzed (bold text below describes the definitions we assigned in our RST analysis, using Mann and Taboada, 2010a as a codebook):

"Nucleus [Email me at (address omitted)] (this is 'an action')

Satellite [and I will forward a glycemic index and a boat load of very useful information. / The information will explain how to use the table and other meal planning help. / The information may help you avoid becoming diabetic.] (this is 'information intended to increase the reader's desire to perform an action' (Mann and Taboada, 2010a)) (ID:Cons_Ans_4.2.2-3-4-5_P3)"

Central to the RST framework are the premises that 1) texts serve various functions, 2) writers/speakers have certain intentions in mind when they communicate, and 3) texts have various effects on their readers. We refer our readers to the actual RST definitions and examples we used in our study analysis (Mann and Taboada, 2010a).

In an RST analysis, the researcher analyzes a text based on the constraints, conditions and definitions in the charts (excerpted below in Table 1 and Table 2) to choose the relation that best describes the functional relationship between two spans of text, and the writer's "intention." Urquhart and Urquhart claim that the phrase above could simply be reduced to: "If you send an email, I will forward you ..." and is therefore a Condition relation. Yes, the text can be reduced; significantly, though, it was not. An RST approach stipulates that the writer/speaker expresses various intentions or goals by their choice of words. The shortened Urquhart and Urquhart version fits the definition of the RST relation Condition, below, because the meaning changes when the relations (and content) are changed - in this case, shortened.

The deciding factor for our choosing Motivation instead of Condition, is that the RST definition of Motivation most accurately described the text's function: that the information in the satellite ("I will send you lots of helpful stuff, with additional details of and about that stuff") is "intended to increase the reader's desire to perform the action" in the nucleus ("email me"). Rather than, as for Condition, that the "reader [simply] recognizes how the realization of (writer sending information - no details given) - depends on the ...reader sending email to the writer" (Mann and Taboada, 2010a, n.p.).

Urquhart and Urquhart's abbreviated example is indeed a Condition relation, but it is not what our participant said/wrote. Urquhart and Urquhart's abbreviated version is lacking important additional information that could convince the reader to "desire" to email the writer (see Azar (1999, p. 101-2) for a similar discussion comparing Motivation and Condition relations that supports our reasoning above). There are fine lines in this type of discourse analysis. RST analysis also takes a long time to learn and to do. But it is possible to do an RST analysis systematically, using the guidelines below, along with other procedures described in other RST studies (cf., Taboada and Mann, 2006a; 2006b; Mann and Taboada, 2010b). 
Definition of Condition

\begin{tabular}{|c|c|c|c|c|c|c|c|}
\hline \multicolumn{2}{|c|}{ Relation Name } & \multicolumn{3}{|l|}{ Nucleus } & \multicolumn{3}{|c|}{ Satellite } \\
\hline \multicolumn{2}{|c|}{ Condition } & \multicolumn{3}{|c|}{$\begin{array}{l}\text { action or situation whose occurrence results from } \\
\text { the occurrence of the conditioning situation }\end{array}$} & \multicolumn{3}{|c|}{ conditioning situation } \\
\hline \multicolumn{8}{|c|}{ Constraints on Conditions } \\
\hline $\begin{array}{l}\text { Relation } \\
\text { Name }\end{array}$ & \multicolumn{3}{|c|}{ Constraints on either $\mathbf{S}$ or $\mathbf{N}$ individually } & \multicolumn{3}{|c|}{ Constraints on $\mathrm{N}+\mathrm{S}$} & Intention of W \\
\hline Condition & \multicolumn{3}{|c|}{$\begin{array}{l}\text { on S: S presents a hypothetical, future, or } \\
\text { otherwise unrealized situation (relative to the } \\
\text { situational context of S) }\end{array}$} & \multicolumn{3}{|c|}{$\begin{array}{l}\text { Realization of } \mathrm{N} \\
\text { depends on realization } \\
\text { of } \mathrm{S}\end{array}$} & $\begin{array}{l}R \text { recognizes how the realization } \\
\text { of } N \text { depends on the realization } \\
\text { of } S\end{array}$ \\
\hline \multicolumn{8}{|c|}{ Example of Condition } \\
\hline $\begin{array}{l}\text { Relation } \\
\text { Name }\end{array}$ & \multicolumn{2}{|c|}{ All of Example Text } & Nuclear Part & \multicolumn{2}{|c|}{ Satellite Part } & \multicolumn{2}{|c|}{ Comment } \\
\hline Condition & \multicolumn{2}{|c|}{$\begin{array}{l}\text { 1. Employees are urged to } \\
\text { complete new beneficiary } \\
\text { designation forms for } \\
\text { retirement or life insurance } \\
\text { benefits } 2 \text {. whenever there is } \\
\text { a change in marital or family } \\
\text { status. }\end{array}$} & $\begin{array}{l}\text { 1. Employees are } \\
\text { urged to complete } \\
\text { new beneficiary } \\
\text { designation forms for } \\
\text { retirement or life } \\
\text { insurance benefits }\end{array}$ & \multicolumn{2}{|c|}{$\begin{array}{l}\text { 2. whenever } \\
\text { there is a } \\
\text { change in } \\
\text { marital or } \\
\text { family status. }\end{array}$} & \multicolumn{2}{|c|}{$\begin{array}{l}\text { The Condition relation has been } \\
\text { grammaticized in English by the } \\
\text { hypotactic conditional clause. However, } \\
\text { comparable to all of the other RST } \\
\text { relations, which are textual relations } \\
\text { rather than grammatical, this relation } \\
\text { need not be expressed with an if clause. }\end{array}$} \\
\hline
\end{tabular}

Table 1. Condition Definition (Mann and Taboada, 2010a, n.p.)

\section{Definition of Motivation}

\begin{tabular}{|c|l|l|}
\hline Relation Name & Nucleus & Satellite \\
\hline Motivation & an action & $\begin{array}{l}\text { information intended to increase the reader's } \\
\text { desire to perform the action }\end{array}$ \\
\hline
\end{tabular}

\section{Constraints on Motivation}

\begin{tabular}{|l|l|l|l|}
\hline $\begin{array}{l}\text { Relation } \\
\text { Name }\end{array}$ & Constraints on either S or $\mathbf{N}$ individually & Constraints on $\mathbf{N}+\mathbf{S}$ & Intention of W \\
\hline Motivation & $\begin{array}{l}\text { on N: N is an action in which R is the actor } \\
\text { (including accepting an offer), unrealized with } \\
\text { respect to the context of N }\end{array}$ & $\begin{array}{l}\text { Comprehending S increases R's } \\
\text { desire to perform action in N }\end{array}$ & $\begin{array}{l}\text { R's desire to perform } \\
\text { action in N is increased }\end{array}$ \\
\hline
\end{tabular}

\section{Example of Motivation}

\begin{tabular}{|c|c|c|c|c|}
\hline $\begin{array}{l}\text { Relation } \\
\text { Name }\end{array}$ & All of Example Text & Nuclear Part & Satellite Part & Comment \\
\hline Motivation & $\begin{array}{l}\text { 2) Ask for SYNCOM diskettes, } \\
\text { with burnished Ectype } \\
\text { coating and dust-absorbing } \\
\text { jacket liners. 3) As your } \\
\text { floppy drive writes or reads, } \\
\text { 4) a Syncom diskette is } \\
\text { working four ways ... }\end{array}$ & $\begin{array}{l}\text { 2) Ask for SYNCOM } \\
\text { diskettes, with } \\
\text { burnished Ectype } \\
\text { coating and dust- } \\
\text { absorbing jacket } \\
\text { liners. }\end{array}$ & $\begin{array}{l}\text { 3) As your floppy } \\
\text { drive writes or } \\
\text { reads, 4) a } \\
\text { Syncom diskette } \\
\text { is working four } \\
\text { ways ... }\end{array}$ & $\begin{array}{l}\text { The Motivation relation is about action } \\
\text { by the reader. In this advertisement it } \\
\text { is buying the product. Units } 3-12 \text { give } \\
\text { many motivating reasons for the action } \\
\text { in unit } 2 \text {. See the Syncom Floppy Disk } \\
\text { Advertisement on this website. }\end{array}$ \\
\hline
\end{tabular}

Table 2. Motivation definition (Mann and Taboada, 2010a, n.p.)

\subsection{More on Claims and Effects}

Contrary to Urquhart and Urquhart's interpretation, we make no claim for the novelty of our approach with regard to studying physician-patient interaction (see also 3.4. above). Our novelty (by now old 
news) claim here is for using RST to study information behaviour related to patient adherence, and the role that peer-to-peer communication might play in adherence.

Moreover, we do not claim that the "effects" we observe in Abrahamson and Rubin (2012) are actual effects, tied to actual human behavior (see also 3.1. above). This is a notion commonly understood by linguistics researchers, when lacking empirical methods to confirm human behaviour. We thought we emphasized this point enough by stating that we used a linguistics approach, and by couching our results or "effects" as being interpreted "linguistically," along with our call for further work that might include user feedback regarding RST effects. This distinction between linguistic and actual effects is vital - hence, we highlight it here. Also important is our agreement with Urquhart and Urquhart that readers should "beware of simplifications and adaptations"- in this case, of our own study narrative.

\subsection{Further Cross-Disciplinary Research Is Needed}

Urquhart and Urquhart urge researchers to exercise caution in crossing disciplinary boundaries which may be interpreted as discouragement from using innovative techniques from outside LIS. You will be sharply criticized for your methods, your assumptions and the literature you never cited. Is it worth it? We believe so. We are optimistic about inter-disciplinary research communication. We would argue that applying a theory from previously disjoint literature does not necessarily constitute a certain lack of rigor. In Abrahamson and Rubin (2012), the RST analytical framework for a systematic analysis of online health communication was a natural fit. It was justified by the insights that RST offers into the language use in computer-mediated health communication and potentially, to peer-assisted adherence to healthy behaviour. We call for continued use of other pragmatic analytical frameworks to the current problem as well as other human information behaviour, in spite of objections from the researchers accustomed to more traditional methods drawn from familiar literature(s).

Lastly, Urquhart and Urquhart engage in a wide-ranging discussion of various areas that can be related to our work, including physician-patient communication and interaction, patient-centred health care, and information and communication technology in health care, in the future, should we garner more generalizable results with further research. However, these discussions are beyond the scope of our 2012 study.

\section{Conclusion}

We appreciate that Urquhart and Urquhart shared some of their concerns and misunderstandings with us, and take this opportunity to ensure that all readers understand the scope of our study and our conclusions. Within computational linguistics, perhaps the ultimate research challenge is to understand the intricacies of human communication well enough that human-to-information-and-communication technology (system) user experience becomes indistinguishable from human-to-human communication. We believe that, due to our history in user-centred research and practice in information behaviour and information retrieval, LIS researchers are uniquely suited to synthesize these two approaches to develop more user-centred information resources to support adherence in chronic disease. We offer our 2012 study as one example for how to move research in this direction, towards improved understanding of human communication and actual information uses, prior to the design of information resources and systems.

We find RST to be a promising framework with which to attempt this integration of information behaviour and information retrieval research approaches, and urge readers to make their own investigations and decisions regarding RST's suitability for such work. 


\section{References}

Abrahamson, J.A., and Rubin, V.L., (2012), "Discourse structure differences in lay and professional health communication", Journal of Documentation, Vol. 68 No. 6, pp. $826-851$.

Azar, M. (1999), "Argumentative text as rhetorical structure: an application of Rhetorical Structure Theory", Argumentation, Vol. 13, pp. 97-114.

Bateman, J., and Delin, J., (2006), "Rhetorical Structure Theory", in Encyclopedia of Language and Linguistics, $2^{\text {nd }}$ ed., Brown, E. K., and Anderson, A., (Eds.), Elsevier, Amsterdam; London: Elsevier, pp. 589-597.

Belkin, N. J., Cool, C., Stein, A., and Thiel, U. (1995), “Cases, scripts, and information-seeking strategies: on the design of interactive information retrieval systems", Expert Systems with Applications, Vol. 9 No. 3, pp. 379-395.

Feng, V.W., and Hirst, G. (2012), "Text-level discourse parsing with rich linguistic features", in Proceedings of the 50th Annual Meeting of the Association for Computational Linguistics: Human Language Technologies (ACL2012), Jeju, Korea, pp. 60-68.

Fleischman, S. (2001), "Language and medicine", in Schiffrin, D. Tannen, D., and Hamilton, H.E. (Eds.), The Handbook of Discourse Analysis, Blackwell, Oxford, England; Malden, MA, pp. 470-502.

Heritage, J., and Maynard, D. W. (2006), "Problems and prospects in the study of physician-patient interaction", Annual Review of Sociology, Vol. 32, pp. 351-374.

Hernault, H., Prendinger, H., duVerle, D.A., and Ishizuka, M., (2010), "HILDA: A discourse parser using support vector machine classification", Dialogue and Discourse, Vol.1 No 3, pp. 1-33.

Lin, Z., Kan, M-Y., and Ng, H.T. (2009), "Recognizing implicit discourse relations in the Penn Discourse Treebank", in Proceedings of the 2009 Conference on Empirical Methods in Natural Language Processing (EMNLP2009), 1, pp.343-351.

Mann, W.C. and Taboada, M. (2010a), "RST definitions", available at: www.sfu.ca/rst/01intro/definitions.html (accessed 10 December 2011).

Mann, W.C. and Taboada, M. (2010b), "RST references", available at: http://www.sfu.ca/rst/05bibliographies/index.html (accessed 18 February 2014).

Mann, W.C. and Thompson, S.A. (1987), Rhetorical Structure Theory: A Theory of Text Organization, Information Sciences Institute, Marina Del Ray, CA.

Mann, W.C. and Thompson, S.A. (1988), "Rhetorical structure theory: toward a functional theory of text organization", Text, Vol. 8 No. 3, pp. 243-81.

Rubin, V. L., and Vashchilko, T. (2012),"Identification of truth and deception in text: application of Vector Space Model to Rhetorical Structure Theory", in Proceedings of the 13th Conference of the European Chapter for the Association for Computational Linguistics: Computational Approached to Deception Detection Workshop, Avignon, France, April 23, 2012.

Rubin V.L., and Lukioanova, T. (In Press), "Truth and deception at the rhetorical Level", Journal of the American Society for Information Science and Technology (JASIST).

Taboada, M. (2004), Building Coherence and Cohesion: Task-Oriented Dialogue in English and Spanish, John Benjamins, Amsterdam.

Taboada, M. and Mann, W.C. (2006a), "Applications of rhetorical structure theory", Discourse Studies, Vol. 8 No. 4, pp. 567-588.

Taboada, M. and Mann, W.C. (2006b), "Rhetorical Structure Theory: looking back and moving ahead", Discourse Studies, Vol. 8 No. 3, pp. 423-459. 